Resenhas 



\section{Raymundo Faoro: intérprete do Brasil em ação}

\section{Leonardo Octavio Belinelli de Brito ${ }^{I}$}

$\mathrm{E}$ MBORA NÃO tenha causado grande repercussão no meio acadêmico quando de sua publicação em 1958 (Ricupero, 2007; Iglesias, 2009), é fato que, em boa medida, Os donos do poder foi o ensaio responsável por colocar Raymundo Faoro (1958) no panteão de "intérpretes do Brasil", posto que ocupa ao lado de autores do quilate de Gilberto Freyre, Caio Prado Júnior, Sérgio Buarque de Holanda, Celso Furtado, entre outros. Com a publicação da segunda edição em 1974 (Faoro, 2008a), consideravelmente aumentada, a posição de Faoro se consolidou, especialmente por três motivos: em primeiro lugar, porque sua tese acerca da prevalência do Estado sobre a Sociedade no Brasil se mostrava particularmente explicativa no contexto autoritário - reforçada pela sua argumentação segundo a qual as Forças Armadas comporiam um dos núcleos do que chamava de "estamento burocrático"; em segundo lugar, pelo fato de $O s$ donos do poder ter sido adotado como referencial teórico para a então emergente ciência política brasileira; ${ }^{1} \mathrm{e}$, por fim, por ter tido uma atuação particularmente marcante como presidente da Ordem dos Advogados do Brasil (OAB) em favor da recomposição das liberdades violentadas pelo regime de exceção que vigia.

Por isso, é de estranhar o fato de que existem relativamente poucas publicações sobre Raymundo Faoro, se comparadas às volumosas bibliografias acumuladas sobre outros "intérpretes do
Brasil”. Essa estranheza é reforçada pelo fato notável de que sua "interpretação do Brasil" é rotineiramente invocada para explicar os males que atingem a política e a sociedade brasileiras. Quem nunca ouviu a tese de que o Brasil é um país patrimonialista? Ou seja: embora tenha se tornado um senso comum - o que é prova de alguma aderência com a realidade -, o conhecimento acadêmico sobre a obra do formulador da tese, a qual não pode ser, de modo nenhum, reduzida a isso, não avançou na mesma proporção.

Oxalá a publicação de $A$ república em transição, coletânea de escritos de Faoro organizada e apresentada por Joaquim Falcão e Paulo Augusto Franco, colabore para a mudança desse cenário. O livro cobre a atividade jornalística do autor de Os donos do poder no período compreendido entre 1982 e 1988, período no qual foi colunista semanal da revista IstoÉ Senhor.

Os 61 artigos de Faoro, aos quais se soma uma entrevista concedida a Maurício Dias, são organizados em quatro partes. Na primeira, intitulada “O 'teatro do poder' e as tramas do oculto (1982-1984)", os textos de Faoro focam a relação entre crise econômica e crise política, combinação tempestuosa para um processo de transição democrática. Na segunda parte, nomeada "A transição com 'T' maiúsculo (1983-1985)", os textos de Faoro são logicamente recortados a partir da discussão que o autor empreendia no processo de definição 
que a transição ocorreria. Já a terceira parte, denominada "A Constituinte e a 'transição imaginada' (1985-1987)", tem como nexo articulador a denúncia do processo que culminou na realização da Assembleia Nacional Constituinte de 1987-1988. Para Faoro, tratou-se de um processo conciliatório que visava fazer uma transição que suprimisse uma efetiva participação democrática dos cidadãos. Por fim, a última parte, cujo título é "Democracia, ficção e a 'retórica do destino' (1986-1988)", reúne textos que fazem considerações desencantadas sobre os desdobramentos da Assembleia Nacional Constituinte de 1987-1988.

Embora os organizadores tenham realizado o esforço louvável de tentar, por meio de notas de rodapé no início de alguns artigos, situar o leitor no contexto no qual Faoro escrevia, é natural que muitos fatos "envelheçam" - isto é, percam a relevância que tiveram em um momento anterior. Mas não há dúvida de que o núcleo da argumentação de Faoro - a análise crítica do processo histórico aberto com a transição do período militar inaugurado em 1964 para o período conhecido como Nova República - ainda nos interpela. Ao mesmo tempo, nos ajuda a repensar a própria figura do autor, tanto no plano das ideias como no plano da ação. É dessa combinação que emana muito do interesse do livro. Vejamos.

Em primeiro lugar, o livro permite ao leitor adotar outra perspectiva em relação ao pensamento de Faoro. Em lugar do intérprete detalhista de Os donos do poder, cuja narrativa começa antes mesmo da formação do Brasil colonial, surge um Faoro ligado aos temas diários, às polêmicas terra-a-terra, ao sabor das incertezas. O contraste serve para corrigir o equívoco daqueles que acusam a "interpretação do Brasil" faoriana de ser anistórica e previamente determinada pelo conceito de patrimonialismo, que seria como que uma enteléquia que resolvesse de antemão, no plano teórico, todos os conflitos políticos portanto, práticos - nacionais. Uma leitura de $A$ república em transição serve de perfeita correção para esse equívoco interpretativo, pois no livro se revela um Faoro profundamente ligado aos desdobramentos dos (aparentemente) mais banais acontecimentos cotidianos para deles extrair seus sentidos mais profundos. Em contraste com a acusação de "abstração", as análises semanais de Faoro resultam, na verdade, numa percepção robusta e desencantada com a força do conservadorismo de nossas elites postas no e ao redor do Estado, causadoras do déficit democrático que assola o país desde sua fundação.

Em poucos termos: interpretação desencantada que Faoro faz do país ganha fôlego no momento em que as esperanças de transformação democrática surgiam em diversos setores mobilizados da sociedade civil. Um exemplo aparece em artigo datado de 8 de abril de 1986, no qual se lê: “A 'transição' tornouse palavra imprestável, o 'entulho' [autoritário], depois das comissões que o revolveram, continua onde estava. A 'transição' não se fez [...]” (p.173). Quase dois anos depois, em 12 de janeiro de 1988, no mesmo tom, Faoro afirma a descontinuidade entre "democratização" e "democracia", na medida em que a primeira não acarretaria, como se supõe corriqueiramente, a segunda. $\mathrm{Na}$ verdade, no caso brasileiro, ocorreria o inverso: a "democratização" prometida no período da transição seria uma 
estratégia hábil para anular um possível processo substantivo de reorganização democrática do país. Em outras palavras: o processo de transição democrática revelava as formas da conciliação com o passado do país contras as quais Faoro se colocava.

O tom grave da advertência assume a forma adequada quando lembramos a observação de Juarez Guimarães, para quem Faoro foi o primeiro pensador a interpretar o Brasil à luz do conceito de liberdade política, "entendida em sua chave republicana, como autogoverno dos cidadãos autônomos" (Guimarães, 2009 , p.80). Nesse sentido, ganha-se muito em ler os artigos coligidos em A república em transição ao lado de Assembleia constituinte: a legitimidade recuperada, ensaio de maior amplitude e ambição escrito no mesmo período. ${ }^{2}$ Um livro ilumina o outro, formando um jogo de luzes e sombras cujo resultado final, embora desalentador - na medida em que destaca a reiterada frustração da sociabilidade republicana no país - é, também, revelador.

Entretanto, é preciso nuançar essa argumentação, na medida em que sua forma mais estilizada acaba por reforçar outra tese unilateral sobre a obra de Faoro: a de que sua interpretação do país é derrotista. A nuança aqui reside em diferenciar dois fenômenos aparentemente relacionados: derrotismo e pessimismo. Embora o segundo esteja presente nos escritos de Faoro, é preciso diferenciá-lo do primeiro. Com efeito, os artigos reunidos em $A$ república em transição permitem observar um intérprete em ação, um intelectual público localizado em um setor estratégico da sociedade civil, a mídia de grande circulação, que lhe permite que sua amplitude reflexiva obtenha a justa ressonância que lhe cabe. Nesse sentido, sua ação, embora embutida de evidente pessimismo, desautoriza qualquer derrotismo prévio. Essa combinação, que Gramsci formulou classicamente da sentença acerca da necessária combinação entre "pessimismo da razão e otimismo da vontade", permite que compreendamos Faoro como um pensador da politica, terreno que se sabe, ao menos desde Maquiavel, incertamente pantanoso e no qual, portanto, é preciso de virtú e fortuna para se locomover. Algo dessa vinculação entre Faoro e Maquiavel - aliás, já presente em Os donos (Faoro, 2008; Brito, 2017) - aparece no parágrafo que fecha o livro, no qual se lê: “O mapa já está pronto. Resta saber se ele leva à mina prometida ou ao inesperado. Nas linhas e no meridiano, há uma incógnita, uma incógnita que se inquieta dentro da crise, terrível e incontrolável. Qual a misteriosa estratégia para domar o terremoto? É o que se verá, em 1988, com certeza" (p.199).

Se esse livro nos permite compreender melhor o contexto histórico e o pensamento de Faoro, ele também nos permite pensar o nosso próprio tempo. Em um momento em que se conjugam diversos ataques à democracia brasileira, cujos ápices são o impeachment de legalidade duvidosa da ex-presidenta Dilma Rousseff (PT), os ataques aos direitos trabalhistas e previdenciários dos cidadãos, o recrudescimento de um conservadorismo raivoso, uma intervenção militar no Rio de Janeiro e a execução da vereadora Marielle Franco (PSOL), os escritos céticos de Faoro voltam a nos interpelar com toda força, revelando a triste atualidade de um clássico do nosso pensamento. 
Notas

1 Para ficarmos em poucos exemplos, de modos variados, Simon Schwartzan (1975; 1988), Maria do Carmo Campello de Souza (1983) e José Murilo de Carvalho (2011) debateram com e a partir da tese de Faoro sobre a formação patrimonial estatal brasileira,

2 Lê-se também com muito proveito $A$ democracia traida, coletânea de entrevistas de Faoro organizada por Maurício Dias e prefaciada por Mino Carta (Faoro, 2008b).

Referências

BRITO, L. O. B. Os dilemas do patrimonialismo brasileiro - as interpretações de Raymundo Faoro e Simon Schwartzman. São Paulo: Alameda, 2017.

CAMPELLO DE SOUZA, M. do C. Estado e Partidos Politicos no Brasil (1930 a 1964). São Paulo: Alpha Ômega, 1983.

CARVAlHO, J. M. A construção da ordem e Teatro de sombras. Rio de Janeiro: Civilização Brasileira, 2011.

FAORO, R. Os donos do poder: formação do patronato político brasileiro. Porto Alegre: Globo, 1958.

. Os donos do poder: formação do patronato político brasileiro. São Paulo: Globo, 2008a.

A democracia traida. Org. e notas Maurício Dias. São Paulo: Globo, 2008b.

. A República em transição. Poder e direito no cotidiano da democratização brasileira (1982 a 1988)". Rio de Janeiro, Record, 2018. 224 p. Organização: Joaquim Falcão e Paulo Augusto Franco.

GUIMARÃES, J. Raymundo Faoro, pensador da liberdade. In: (Org.) Raymundo Faoro e o Brasil. São Paulo: Fundação Perseu Abramo, 2009.
IGLESIAS, F. Revisão de Raymundo Faoro. In: GUIMARÃES, J. (Org.) Raymundo Faoro e o Brasil. São Paulo: Fundação Perseu Abramo, 2009.

RICUPERO, B. Sete lições sobre as interpretações do Brasil. São Paulo: Alameda, 2007.

SCHWARTZMAN, S. São Paulo e o Estado nacional. São Paulo: Difel, 1975. Bases do autoritarismo brasileiro. 3.ed. Rio de Janeiro: Campus, 1988.

Leonardo Octavio Belinelli de Brito é doutorando em Ciência Política pela Universidade de São Paulo (USP).

@ - belinelli.leonardo@gmail.com /

https://orcid.org/0000-0002-4622-5366

Recebido em 29.3.2018 e aceito em 6.5.2018.

I Faculdade de Filosofia, Letras e Ciências Humanas, Universidade de São Paulo, São Paulo, São Paulo, Brasil. 